\title{
Leadership and Entrepreneurship in Tech Start-UPS
}

\author{
Corina Georgiana Serban (Patrintas) ${ }^{1}$ \\ Cristian Negrutiu ${ }^{2}$
}

\begin{abstract}
The present paper attempts to deal with two classical themes in a new and fresh context. The amount of works on leadership and entrepreneurship is vast, but the authors identified a gap in the research of these concepts in relation with tech start-ups, a domain that developed significantly in the recent period.

The authors performed a detailed literature review, followed by an interview with a selected panel of entrepreneurs in Romania. The results of the study highlights few important trends related to the leadership traits of Romanian entrepreneurs. The results also confirmed a positive mindset and attitude which triggers an optimistic outlook. for the Romanian entrepreneurial ecosystem.
\end{abstract}

Keywords: Leadership, entrepreneurship, start-ups, Romanian ecosystem, supply chain, interview

JEL Classifications: L26, L90, M13, M50, O36

DOI: $10.24818 / \mathrm{REJ} / 2021 / 82 / 02$

\section{Introduction}

Leadership has been recognized as the capacity to persuade others to follow. It was identified as main aspect that inspires and influences employees' behavior and results (Chen Tang Jin et al, 2014, quoted by Bagheri et al., 2017, pp 159) having an undeniable impact within the organizational success.

On the other side, entrepreneurship has been acknowledged as more than running an existing small business, including concepts as change management, creative thinking, opportunity seeing and innovativeness (Mattare, 2008, quoted by Bagheri et al., 2010, pp 470).

\footnotetext{
${ }^{1}$ Bucharest University of Economic Studies, e-mail: corinasrn@yahoo.com

${ }^{2}$ Bucharest University of Economic Studies, e-mail: cristian_negrutiu@yahoo.com

Year XXIV no. 82
}

December 2021 
The concept of entrepreneurship is also closely linked with leadership. Mintzberg (1979) clearly underlines that every entrepreneur is also a leader that needs to drive the business that he created in a professional way.

The relation between leadership as a driver for entrepreneurship is researched also by Felix, Aparicio and Urbano (2018). First of all, as a general rule, the authors sustain that entrepreneurship is positively related to leadership. However, at a more detailed insight, there is more than one leadership style and, similar to Yan and Yan (2016) approach, the authors identify several other causalities. Charismatic leadership and participative styles of leadership have a positive influence on entrepreneurship, while autonomous leadership has a negative effect, although moderated by humane dimension. The conclusion of the study is that entrepreneurs are an important type of strategic leaders and the relation between the two concepts requires further and specific investigations.

In this context, entrepreneurial leadership differentiates as the intersection between entrepreneurship and leadership (Cogliser and Brigham, 2004, quoted by Nguyen et al. 2021, pp 2). Although the literature describes two opposing opinions regarding the concept, one considering that it is part from a larger leadership context, that can be integrated into entrepreneurship, while the other insists it differentiates as a separate concept (Kimbu et al., 2021), lately it has gathered reasoning through lengthy studies. An explanation can be the need to bring forward leadership styles that answer and are coherent with the present entrepreneurial scenario (Nguyen et al. 2021).

As the practice of start-ups becomes more popular, entrepreneurship can be found in all economic sectors and countries and supply chain makes no exception. The present paper will address the status of this sector in Romania, it's challenges and prospects for the future as well as the relation with entrepreneurial leadership.

\section{Review of the scientific literature}

\section{Entrepreneurial leadership}

The research on the subject has begun in 1991 when Cunningham and Lischeron defined it as the process of goal setting, creating opportunities, empowering individuals, maintaining intimacy and forming HR systems. A more recent definition was provided by Ngyuen et al. (2021, pp. 1), quoting Gupta et al. (2004), that noted that entrepreneurial leadership represents the organization and motivation of employees and processes to succeed to obtain the company's objectives, such as taking risk, seizing opportunities, innovating products and processes, creating competitive advantages, and improving dynamic competencies, 
considering it an antecedent of the entrepreneurship success brought through innovation.

Mishra and Misra (2017) have identified entrepreneurial leadership to be comprised of three dimensions. The first dimension is considered as the "directed discovery" that refers to envisioning a path into the ambiguous future and redirecting as events unfold. It reunites elements as "framing" that includes performance orientation, intuition, ambition and decisiveness, as well as "absorbing uncertainty" that refers to foresight, vision and confidence building and "underwriting" that comprises convincing, diplomacy and bargaining. The second dimension is "creative integration" that encompasses actions regarding human and non-human resources. Finally, the third dimension is "arena building" where the leader focuses on product development.

In this setting, entrepreneurial leadership competencies, considered as those leadership capabilities mandatories for effectively leading competitive and challenging processes, have been recognized as vital, both in start-ups and established companies (Yang, 2008, quoted by Bagheri et al, 2010, pp 471). The personal competencies of entrepreneurial leaders allows them to positively regard the future of their company through an innovative vision and seizing the opportunities, while functional competencies empower leaders to influence and inspire their followers to renounce their current and conservative tasks performance and outspread their energies to fulfill innovative and entrepreneurial activities (Gupta et al, 2004, quoted by Bagheri, 2017, pp 161).

In small ventures, leaders are largely thought to hold a solid imprinting effect due to lack of complicated structures and scarcer behavioral rules. Therefore, they may show a higher level of discretion, and subsequently have a more substantial impact on firm strategies and performance (Nguyen et al, 2021).

It has been argued that in the case of entrepreneurs, the opinions and expectations of others are of top importance as it's their beliefs and expectations that effect their evaluation and their capacity to obtain legitimacy (Johnson et al, 2008, quoted by Rudiac et al., 2021, pp. 1). Rudiac et al. (2021) noted that potential employees will pay much more attention to their perception of the entrepreneur and especially their leadership capabilities, as they represent organizational "face" and possible future people leaders. The stereotypes around entrepreneurial leaders could be connected to the implicit leadership theories related to specific expected behaviors and demographic stereotypes. These beliefs could play an even more important role due to entrepreneurs' accountability for all actions and their employees. 
The Implicit Leadership Theories developed by Robert Lord (1984) sustain that individuals create cognitive representations (in this case of their leader) and use them to create a prototype with which they compare their surroundings. Followers have implicit expectations related to personal characteristics, traits, and qualities of a specific leader. Through the GLOBE study (House et al, 2002), it was showed that the expected traits will be shared by individuals from same cultures. Ute and al. (2016) have mentioned that "entrepreneurship will flourish in cultures where cultural leadership ideals align with entrepreneurial behaviors". Apart from that, there are other factors that shape these characteristics as: gender, personality, hierarchical level, experience with leaders and own leadership experience. Gupta and Fernandez, 2009, quoted by Rudiac et al. (2021, pp1) also noted that people may hold a mental image of what they expect that entrepreneurs typically behave and look like or how they should behave and look.

Numerous studies quoted by Rudiac et al. (2021) have all agreed that entrepreneurs are or are expected to be young, tough, extroverted and confident risktakers, focused on entrepreneurial success, with good communication skills and persuasions capabilities in order to be able to convince others to follow their goals and vision. Chan et al. (2015) have demonstrated the positive correlation between the Big Five personality traits (openness, conscientiousness, extraversion, agreeableness, and neuroticism), low risk averseness and proactive personality with both entrepreneurship and leadership skills. In all the studies, the entrepreneurial leaders are either depicted or suggested to be young males or to possess masculine traits. Clemens et al., 2018 argued that a higher importance positioned on extrinsic rewards, stimulation and autonomy; and a lower importance placed on security and social/ interpersonal aspects of work foresee elevated entrepreneurial ambitions.

Kimbu et al (2021) noted that women entrepreneurial leaders come to be viewed as lacking when compared to the all present masculine model. In fact, masculinity holds its' position in time also in the case of leaders' implicit theories expectations in all the studies performed both by Offermann (1994 \& 2018) and Epitropaki and Martin (2004). So, while the number of people engaging in start-ups has increased, we cannot say the same thing about the number of women.

Based on above research, we formulate the following hypothesis:

Hypothesis 1 (H 1): Most entrepreneurial leaders are males

Hypothesis 2 (H 2): Entrepreneurial leadership characteristics are positively linked with those characteristics related to the ethical and transformational leadership style. 
Another factor that can influence the capacity of people to become entrepreneurship leaders is the congruence between the image they have on leaders in general, and how they see themselves. Schyns et al. (2020) has showed the fact that individuals who perceive themselves as possessing similar characteristics to their ideal leadership traits schema are more likely to pursue a career in this field. Bagheri et al. (2010) has argued that the learning process in the case of entrepreneurial leadership is divers and can refer to either learning by performing (gain experience), social interaction (interact with entrepreneurial people), observation (directly observing) or reflection (deep thinking). The process of entrepreneurial learning is done in 2 steps: pre-launching (cognitive process of gaining and structuring knowledge and skills) and post-launching (gaining experience by doing tasks and taking roles that allow entrepreneurship learning).

Based on above research, we formulate the following hypothesis:

Hypothesis 3 (H 3): Entrepreneurial leaders' traits are close of the traits they envision for their ideal entrepreneurial leader.

Nguyen et al. (2021) stated that an implicit connection exists between entrepreneurial leadership and business performance since the performance is a result of leader's strategy. Innovation has been identified as a main requirement and driver of entrepreneurial leadership. They also influence the organizational competitiveness and the ability to develop an entrepreneurial vision, using their specific characteristics to improve their effectiveness.

Entrepreneurial leadership has a diverse area of impact within organizations, that goes beyond innovation and performance, that include competitiveness, success and business development (size, type, structure) (Freeman, 2014 quoted by Bagheri, 2017, pp 160).

\section{Entrepreneurial leaders and impact on innovation}

Identified as main predecessor of entrepreneurial leadership, entrepreneurial success is highly connected to leaders that encourage followers to think and act through creation and innovation (Gupta et al., 2004, quoted by Nguyen et al., 2021, pp. 2). Innovation refers to the generation and application of new ideas, processes and products (Montani et al, 2017). In the all-fast moving, technology driven environment of today, innovation is singled out as an essential strategy that is vital to the performance, growth, and survival of the company, directly influencing the lifespan of an organization. 
Omar and Morales (2020) noted that especially in the case of small ventures, they fail in short term due to issues such as lack of investment in improvement and market knowledge, poor planning and lack of managerial skills and low economical resources. It is comprised from product innovation, process innovation and management systems innovation, being noted that product innovation is the main aspect that influences the capability of organizations to be resilient. However, in the case of SMEs, the high costs and risks that innovation implies, makes innovation directly reliant of the individual that should possess such traits as to bring after him the organizational innovation. Oluwafemi et al. (2020) has noted that flexibility and situational adaptability could be the most important characteristics of the ambidextrous leader, by ambidextrous being understood both the exploration of new as the exploitation of the existing.

Janssen et al, 2000 has described innovation as a dual process related to behaviors that foster idea generation and behaviors that foster idea realization. The idea generation is connected to new and unexplored ideas useful to any field, and implies personalities that are defined as creative, willing to learn and explore. Idea implementation denotes being able to produce the prototype that can be tested and ultimately can be applied. Innovation necessitates a mindful outlay of resources such as time, energy and focus.

Xie et al. (2018) have conducted a study regarding the leadership style and the innovation atmosphere within an organization. Transformation leadership style has been identified as being able to promote trust and individual identification, being most accommodating for encouraging innovation atmosphere. While atmosphere within an organization was acknowledged to be impacted by the leadership behavior, culture, and values, trust impacted creative behavior by affecting the thinking patterns and values. Through the main definition of leadership, trust is a vital outlet to leadership, that is based on how they can influence others to voluntarily follow into the accomplishment of collective objectives.

Innovative leadership is regarded as fostering encouragement for people's ideas, acknowledging responsibility, feedback, and trust (Oluwafemi et al., 2020).

Lee and Trimi (2021) have identified that innovation is a crucial aspect as an answer to crises. Most true in the case of SMEs, that lack developed strategies, the actual time of response through innovation is an important factor to be considered. Recently, due to technology development, science digital transformation of organizations, the rhythm of innovation has been frantic. innovation, organizations will be able to compete through capabilities such as agility, flexibility, resilience, and speed. Of course, that in the case of small 
ventures, these characteristics will apply directly to the main driver of the company, the entrepreneurial leader.

\section{Entrepreneurship in tech supply chain start-ups}

Innovation is very often associated with entrepreneurship. According to Schumpeter (1934), through the process of creative destruction, the entrepreneur destroys the old paradigm and, helped and driven by innovation, creates new products/services and ideas that fosters economic growth. This central idea was further developed by other eminent thinkers, like Mises, Drucker or Gartner, who points out to pivotal role of the entrepreneur in the economy.

In a comprehensive study, Yan and Yan (2016) present the impact of individual entrepreneurship and collective entrepreneurship on innovation in small business. The authors start their research with two important framework theories, the leadership imperative theory, presented by Miller (1983) and the collective entrepreneurship theory, developed by Reich (1987). However, these theories address innovation only the in the context of individual entrepreneurship (Miller) or collective (Reich), so the authors tried to integrate the concepts in unified research. To this end, they formulate and demonstrate few research hypotheses that showed the innovation positively influence the entrepreneurs in decision making processes, internal locus of control and knowledge about emerging markets, products, and technologies.

The relation between social entrepreneurship and leadership is analyzed also by Muralidharan and Pathak (2018). Sustainability is a key concept nowadays and the authors define social entrepreneur as a special type of entrepreneur that has a behavior focused on "recognition, evaluation and exploitation of opportunities to address the basic needs of the societies". So, the social entrepreneur is driven by profit, as any entrepreneur, but with a solid sustainability focus in mind. These beliefs are strongly influenced also by the leadership style and traits of the entrepreneur, which the authors define as transformational leadership. Their findings also demonstrate a direct causality between transformational leadership and the desire to start a social entrepreneurial journey. Macro factors, like a socially supporting culture, also played a significant role. In order to prove their findings, the authors used a random-effect logistic regression model, based on an OLS analysis.

Although entrepreneurship starts usually at individual level, very quickly, as the company develops, the founder needs to attract talents that will continuously support the innovation. In this context, the leadership qualities of the 
entrepreneur are extremely important, as demonstrated by Laguna et al (2019). The authors performed a cross-countries investigation on the relation between entrepreneur's authentic leadership and the employee's innovative behavior, finding not only a positive correlation, but also another two enablers and mediators between the two factors. These are 1. personal initiative and 2 . work engagement, which, together with national culture, form a virtuous cycle of continuous innovation.

The topic of entrepreneurial management and employee innovation is further investigated by Korpysa, Halicki and Lopatka (2020). Citing the seminal works of Peter Drucker, the authors note that any entrepreneurial journey in management is based on the existence of teams of employees with the favorable skills. Drucker also mentions another pre-requisite for an entrepreneurial management, in the form of a customer centric approach. A company that adopts an entrepreneurial management style can achieve superior results in terms of performance efficiency and strategic flexibility. After the general considerations, the authors analyze how supply chain is influenced by entrepreneurial management and what are benefits of using such an approach. First, they define supply chain as "a concept that aims at delivering products and services to the customer through the activities of organizations, people, and technology". Usually, supply chain is performed via projects, that involves several suppliers, sub-contractors and a main contractor with the scope of serving the customer. As expected, the principal contractor has the most important role in organizing the supply chain, as it is responsible for managing the flow of resources between the actors of the supply chain. As such, the main contractor must take strategic decisions and an entrepreneurial management is key in maintaining alignment in the supply chain, through a seamlessly flow of information.

Sustainability is key concept in supply chain. We have addressed above the concept in relation with entrepreneurship, it's now time to see it in a larger concept. Tipu and Fantazy (2018) proposed a model integrating social capital, strategic entrepreneurship, sustainable supply chain management and organizational performance. By using a fitted structure equation model, the authors not only demonstrate the positive correlation between the four concepts, but also the central role of sustainable supply chain management.

Based on above research, we formulate the following hypothesis:

Hypothesis 4 (H 4): Innovation and sustainability are key pre-requisites for any entrepreneurial journey. By applying consequently these two characteristics, the entrepreneurs can disrupt their industries.

Year XXIV no. 82

December 2021 
Li and Holsapple (2018) looked at the supply chain from a network perspective, instead of a project. The authors define four types of networks: receptive, traditional, opportunistic and entrepreneurial. The last one is characterized by high level of trust and integration between participants as well as a non-redundant information sharing. From the superior characteristics of this network, the authors derive the general framework of supply chain entrepreneurship, as depicted in Figure 1.

Figure 1. Framework of supply chain entrepreneurship, adapted after $\mathrm{Li}$ and Holsapple (2018)

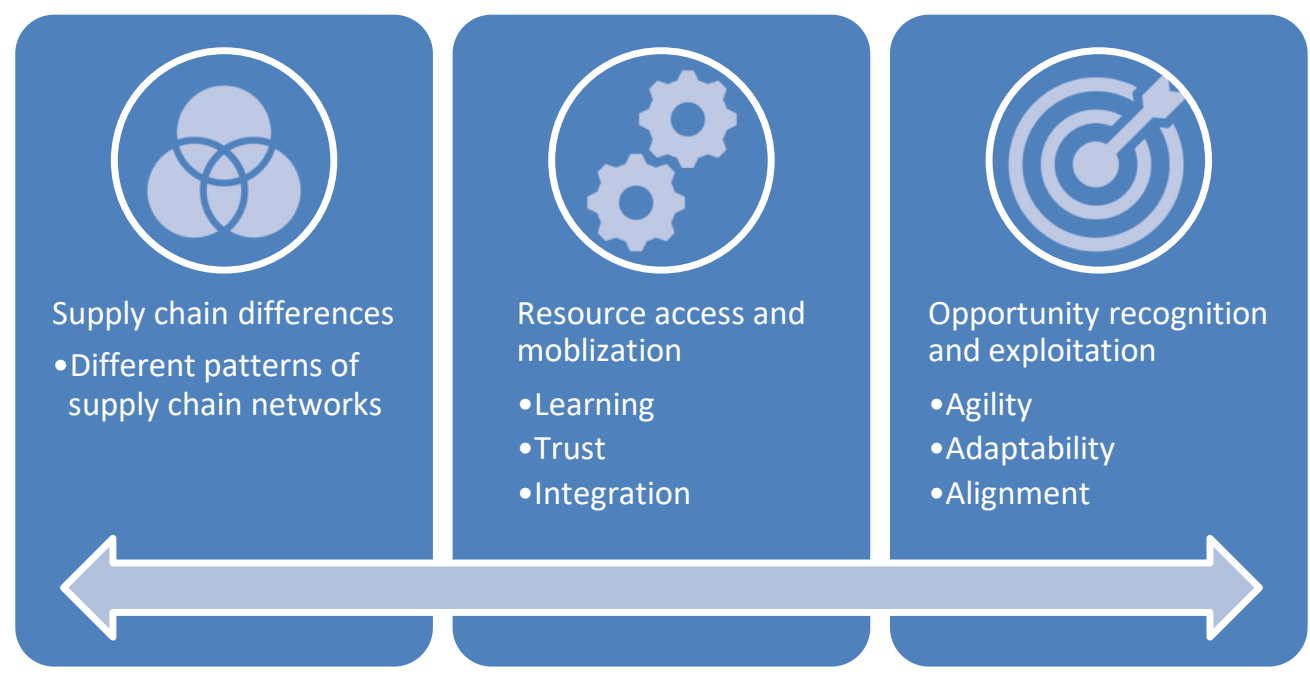

\section{Research methodology}

To complement the literature review, a semi-structured interview was piloted to a selected number of entrepreneurs. In the period August - October, a total number of 20 entrepreneurs replied to the research initiated by the authors. The structure and the content of the interview can be found in Appendix 1.

This study aims to gather informations regarding the experiences and perceptions of the entrepreneurship leaders developping their activity in Romania. The interviewed subjects have entrepreneurship experience, therefore we aim to give an actual updated view of this field, using the semi-structured interview format.

The sample is a group of people representing business owners of micro and small entreprises. To choose this sample there were used the data and connections obteined through the participation to a Romanian Entrepreneurs Association. The members were there contacted by phone or email to obtain the approval to 
participate to the interview and set up the necessary details. The written notes will be analyzed to underlyne the repetitive results.

The interview was divided in four sections comprising Introductory questions, Impact on innovation and sustainability, Leadership traits of entrepreneurs and Outlook. All of them were compulsory, as we tried to capture several aspects of leadership and entrepreneurship. Also, it was aimed a good mixture of open and closed questions.

Based on the structure of the interview, we formulate a supplementary research hypothesis.

Hypothesis 5 (H 5): Entrepreneurs have a positive sentiment regarding their start-up and industry, in general. They are ready to take advantage of the current opportunities and transform them into real business results.

This study has practical implications for the entrepreneurs in Romania as well as for the next generations that can understand what defines an entrepreneurial leader.

The study has the following limitation (a) limited generalization as it is limited to a small number of respondents, part of an association (b) the possibility that the author's own opinions influence the results interpretation.

\section{Results and discussion}

The results of the analysis will be presented using the sections of the interview. Initially, the respondents were asked to answer few qualifications questions, like age, sex and number of years of experience (1. Total; 2. Entrepreneurial; 3. In current start-up). Other qualifications questions were related to their business and included the number of employees and current monthly recurring revenue (MRR). In this preliminary section, the entrepreneurs were asked to describe briefly how they started their current business.

In terms of sex, $94 \%$ are men, which clearly confirms an obvious trend in Romania - many of the entrepreneurs are still men. This trend readily aligns to the international context, that still consider women as lacking in both entrepreneurial and top leadership endeavors and with the results of the implicit leadership theories studies that maintain "masculinity" as a top expected trait of the leader. The well-known saying "think leader, think male" still holds its' power on both males and females in their working environment, this being a viable explanation for the huge gender discrepancy. Moreover, especially in entrepreneurship, the "willingness to take risks" is considered as a defining characteristic, that ranked on 
the first place on the entrepreneurs' self-assessed traits in our interview (69\%), together with "openness to new", a highly related characteristic, and on second place $(68.8 \%)$, after "emotional intelligence" $(75 \%)$ on the ideal entrepreneur/leader characteristics. Considering that in stereotypical thinking, women are considered less risk takers than men and more prone to stability, lacking the power a man possess and being more emotional instable (Vial et al (2016), the results of our study confirm the status quo of gender inequality at entrepreneurial level (H1).

Hypothesis 1 is confirmed: Most entrepreneurial leaders are males

As regards to age, $56 \%$ of the respondents are between 35 and 45 years, which shows that we are speaking about experienced people. This trait is confirmed also by the number of years of professional experience, where $56 \%$ have more than 15 years. Although aligned to the experience expected from a leader, this comes as a surprise when comparing to the international trends that expect entrepreneurs to be not only risktakers, but young, tough, and extroverted (several studies quoted by Rudiac et al., 2021). The age and experience gap might be explained through the cultural aspect, considering that due to communism the entrepreneurship in Romania lacks history and experience, therefore young people must learn it through experience more than seeing around them, and in order to do so, the majority of them first experiences stable employment, than take contact with other start-ups or gather the courage to take the step to entrepreneurship. As for the extroversion, the respondents of the interview have not name it as an ideal entrepreneurial leaders' trait (less than $1 \%$ ), nor often as a possessed characteristic $(12 \%)$. The explanation might be the pejorative meaning that the word could have in Romanian, more often than not being perceived rather as a flaw, than a quality. The same can be implied for the "toughness" characteristic, that is seen as mandatory in the international leadership studies, as well as a lacking trait in females that makes them less appropriate candidates for leadership positions.

The respondents of the interview have completely disregarded the ability of an entrepreneurial leader to impose himself in front of others (less than $1 \%$ ), both in ideal leaders, as well as their own traits. Also, the "strength" characteristic, that is regarded as the positive counterpart of "toughness" has barely reached $18.8 \%$ for the ideal leader chosen traits and $25 \%$ in the possessed characteristics. This might show a trend of rejection for the autocratic leader that was so often seen in the communist era and aligning to newer leadership trends that revolve around inspiration, fairness, and charisma. In fact, for the ideal entrepreneurial leader characteristics resulted from the interview, apart from the above mentioned "emotional intelligence" and "willingness to take risks", communication (68.8\%), "dedication" (50\%) and "persuasion" (50\%) have ranked over $50 \%$, all of these 
being attributes of the transformational as well as ethical leadership style. The same is reflected by the answers of the respondents to the question of what motivates their followers, $68.8 \%$ naming "the possibility to express themselves" and $62.5 \%$ naming "believing in a common goal", both showing that from the leaders point of view their followers are expecting from them to possess the traits necessary to create these conditions. This was confirmed also by the respondents that named their leadership style most often as "transformational" $(31.3 \%)$, being overpassed closely only by the "ethical leadership style" that is considered as the ability to create a responsibility sense around all stakeholders, through motivation, communication and the capacity of choosing to do the "good thing" for all the parties involved (H2). Entrepreneurial leadership in Romania is therefore driven by the wish to inspire others and the wish to be correct, although other leadership styles might still be visible - democratic (12.5\%), laissez-faire (6.3\%), transactional and autocratic (under 5\%).

Hypothesis 2 is confirmed: Entrepreneurial leadership characteristics are positively linked with those characteristics related to the ethical and transformational leadership style.

Regarding the theory of Schyns et al, 2020, that considered that the persons that become leaders have similar IST (Implicit Self Theories - self seen characteristics) with the ILT (Implicit Leadership Theories - ideal leader characteristics), the proposed interviews confirmed that, the answers to the two questions (ideal leader traits and self-assessed characteristics) being indeed similar, with no major variations $(\mathrm{H} 3)$.

Regarding the motivation to become an entrepreneurial leader, a differentiation was made through the interview between the two aspects: entrepreneur and leader. As per the received answers the motivation differs indeed on becoming an entrepreneur and becoming a leader, suggesting that the respondents could have considered and intended the entrepreneurship, the leadership aspect being gained due to the correlation between the two. A bridge between the two is the motivation to overpass challenges $(68.8 \%$ in entrepreneurship and $56,3 \%$ in leadership) that leads again to the main characteristic of the entrepreneurial leader: the ability to take risks. For the entrepreneurship motivation, a very high importance has the "self-reliance" sense $(68,8 \%)$, as well as "contributing to a field/ community" (62.5\%) and "being allowed to be creative" (62.5\%), while for the leadership part, a main aspect is seen as "leading a team" (50\%).

Hypothesis 3 is confirmed: Entrepreneurial leaders' traits are close of the traits they envision for their ideal entrepreneurial leader.

The second theme of the interview referred to the perceived impact of the startup from the entrepreneur point of view. We have researched the impact based on 
three pillars - innovation, disruption and sustainability, asking the participants to rate the impact into three categories - high, medium, low. The results proved the entrepreneurs perceived their business as having a high impact on disruption $(50 \%)$, innovation $(64 \%)$ and sustainability $(58 \%)$. The scores indicate the focus of the entrepreneurs more into efficiency and disruption, which is aligned with their initial objectives. Usually, a tech start-up aims to improve the efficiency of an industry and, through this efficiency, to even disrupt it. Innovation and, especially, sustainability are important also, but more viewed because of the first two characteristics. The example of Uber is paradigmatic for a mobility start-up, as they didn't invent a new industry, but merely disrupt it through technology.

Hypothesis 4 (H 4) is confirmed: Innovation and sustainability are key pre-requisites for any entrepreneurial journey. By applying consequently these two characteristics, the entrepreneurs can disrupt their industries.

The last part the interview was dedicated to the entrepreneurs' perception on the future. Most of them are optimistic regarding their industry and business, scoring more $80 \%$ on both categories, which is line with the same positive mood that we captured at the first section. However, to have a more detailed view on the future, we have asked the entrepreneurs to self-assess a pre-defined SWOT analysis, as depicted in Figure 2.

Figure 2. Results of the SWOT analysis

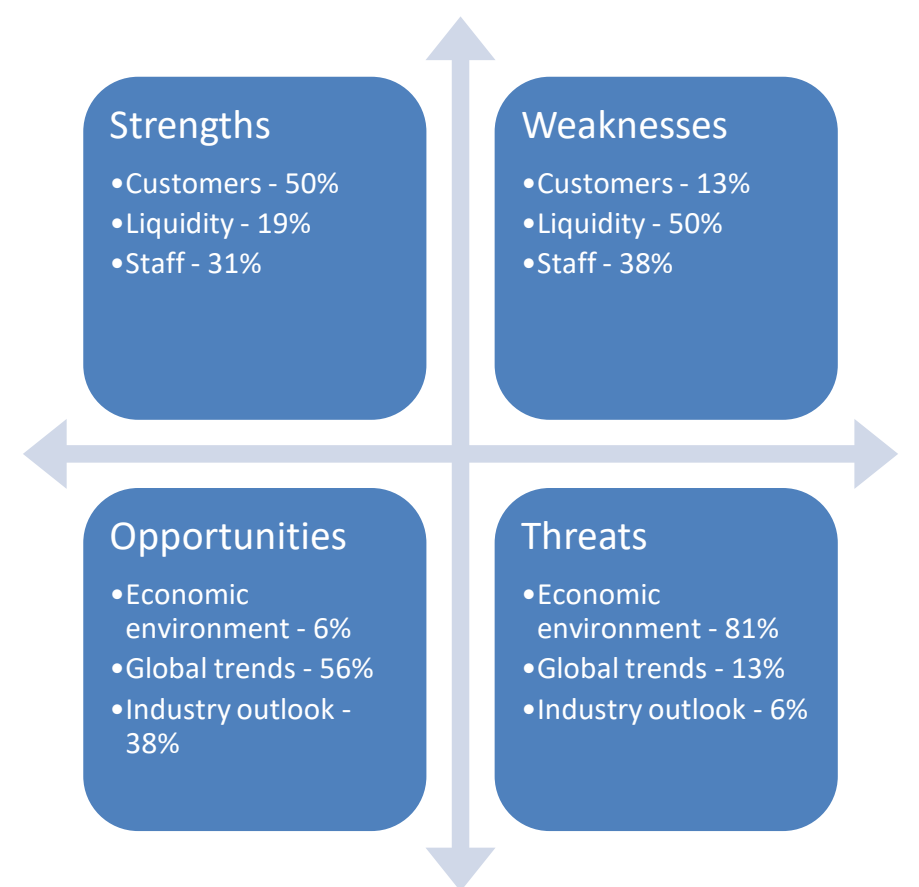

Year XXIV no. 82

December 2021 
The SWOT analysis reveals a much more complex picture of reality, both in terms of internal factors (strengths and weaknesses) and external factors (opportunities and threats). Customers are the most important strength mentioned by entrepreneurs, which is somehow normal in this early-stage start-ups, whereas customer acquisition is the most important task. The same explanation is valid also for weaknesses, where liquidity plays a pivotal role, as for all early-stage businesses that are living on the edge. On the external factors, we see a little bit of contradiction on both quadrants, whereas economic environment scores very low in opportunities and very high on threats, whereas global trends and, partially, industry outlook, have almost the opposite scores. Most likely, the entrepreneurs look at the economic environment from a national perspective, while global trends and industry outlook are viewed more at regional and global level (as the name suggests).

Hypothesis 5 (H 5) is confirmed: Entrepreneurs have a positive sentiment regarding their startup and industry, in general. They are ready to take advantage of the current opportunities and transform them into real business results.

\section{Conclusions}

The research on entrepreneurship and leadership in supply chain has revealed interesting perspectives.

All the entrepreneurs that participated in the survey have an optimistic view on the future. This may be a characteristic of all entrepreneurs in the world (since, otherwise, they wouldn't have started their business), but, for our case, we noticed a constant and high level of optimism. More importantly, this positive attitude is not related to the economic environment of Romania, but merely to the global trends that the entrepreneurs try to capture. The optimist vision is perceived also in other aspects, like access to resources and exit prospects.

In respect to the entrepreneurial leadership, the study has demonstrated the positive link between those characteristics related to the ethical and transformational leadership style, and a separation trend of the communist autocratic values. The portrait of the Romanian entrepreneurial leader contours as an experienced male, willing to take risks and opened to new that places high value on emotional intelligence and communication skills. What is outstanding from the results is that although they place high value on new experience and risk taking, being innovative did not stand out as a mandatory or major trait, implying that the majority actually prefers tested methods and tools when opening a new venture. Furthermore, the image of their ideal entrepreneurial leader traits stands 
very close of their own image, in accordance with Schyns et al. (2020) theory that states that humans seeing themselves as possessing similar characteristics to those of the ideal leader are more probably to act and actually end up in such positions.

The limits of the study reside in the panel that we have designed from the beginning. Our research considered only entrepreneurs active in tech start-ups from supply chain and related verticals. As such, the results are valid only to this category and cannot be extended to other entrepreneurs. Our intention is to continue the research by focusing and narrowing down specific topics that were treated here in a more general way.

\section{References}

Amedofu, M., Asamoah, D., Agyei-Owusu, B., 2019. Effect of supply chain management practices on customer development and start-up performance. Benchmarking, 26(7), pp. 2267-2285

Bagheri, A., 2017. The impact of entrepreneurial leadership on innovation work behavior and opportunity recognition in high-technology SMEs. Journal of High Technology Management Research, 28, pp. 159-166

Bagheri, A., Pihie, Z. A. L., 2010. Entrepreneurial Leadership Learning: In Serach of Missing Links. International Conference on Learning Diversity 2010, Procedia Social and Behavioral Sciences, 7(C) (2010), pp. 470-479

Chan, K. Y., UY, M. A., Chernyshenko, O. S., Ho, M. H., Sam, Y. L., 2015. Personality and entrepreneurial, professional and leadership motivations. Personality and Individual Differences, 77, pp 161-166

Clemens, M. L., Sortheix, F. M., Obschonka M., 2018. What drives future business leaders? How work values and gender shape young adults' entrepreneurial and leadership aspirations. Journal of Vocational Behavior, 107(2018), pp. $57-70$

Epitropaki, O., Martin R., 2004. Implicit leadership theories in applied settings: Factor Structure, Generalizability and Stability over time. Journal of Applied Psychology, 89(2), 293-310

Felix, C., Aparicio, S., Urbano, D., 2019. Leadership as a driver of entrepreneurship: an international exploratory study. Journal of Small Business and Enterprise Development, vol. 26, no. 3, pp. 397-420.

House R., Javidan M., Hanges P., Dorfman P.W., 2002. Understanding cultures and implicit leadership theories across the globe: an introduction to project GLOBE. Journal of World Business, Vol 37, No 1, pp. 3-10

Janssen, O., 2000. Job Demands, perceptions of effort-reward fairness and innovative work behaviour. Journal of Occupational and Organizational Psychology, 73(3), pp. 287-302 
Kimbu, A. N., de Jong, A., Adam, I., Ribeiro, M. A., Afenyo-Agbe, E., Adeola, O., Figueroa-Domecq, C., 2021. Recontextualising gender in entrepreneurial leadership. Annals of Tourism Research, 88(2021), 103176

Korpysa, J., Halicki, M., Lopatka, A., 2020. Entrepreneurial management of project supply chain - a model approach. Problems and Perspectives in Management. vol. 18, no. 3, pp. 211-223.

Laguna, M., Walachowska, K., Gorgievski-Duijvesteijn, M., Moriano, J.A. 2019. Authentic Leadership and Employees' Innovative Behaviour: A Multilevel Investigation in Three Countries. International Journal of Environmental Research and Public Health, vol. 16, no. 21.

Li, X., Holsapple, C.W., 2018. Bring Entrepreneurship into Supply Chain Partner Networks: The Influence on Best-value Supply Chains. Journal of Strategic Innovation and Sustainability, vol. 13, no. 3, pp. 85-98.

Lord, R.G., Foti, R.J., Alliger, G.M., 1984. A test of leadership categorization theory: Internal structure, information processing and leadership perceptions. Organization Behaviour and Human Performance, Vol 34, pp. 343-378

Mishra, P., Misra, R. K., 2017. Entrepreneurial Leadership and Organizational Effectiveness: A comparative Study of Executives and Non-Executives. Information Technology and Quantitative Management (ITQM), Procedia Computer Science, 122, pp. 71-78

Montani, F., Courcy, F., Vandenberghe, G., 2017. Innovation under stress: the role of commitment and leader member exchang. Journal of Business Research, 77 (2017), pp. 1-13

Muralidharan, E., Pathak, S., 2018. Sustainability, Transformational Leadership, and Social Entrepreneurship. Sustainability, vol. 10, no. 2, pp. 567.

Nguyen, P. V., Huynh, H. T. N., Lam, L. N. H., Le, T.B., 2021. The impact of entrepreneurial leadership on SMEs' performance: the mediating effect of organizational factors. Helyon, 7(2021), e07326

Offermann, L.R., Coats, M.R., 2018. Implicit theories of leadership: Stability and change over two decades. The Leadership Quarterly, 29, 513-522

Oluwafemi T.B., Mitchelmore S., Nikolopoulos K., 2020. Leading innovation: Empirical evidence for ambidextrous leadership from UK high-tech SMEs. Journal of Business Research, 119 (2020), pp. 195-208

Omar, S., Morales, C., 2021. Innovation as Recovery Strategy for SME's in Emerging Economies during the Covid 19 Pandemic. Journal pre proof available online at https://doi.org/10.1016/j.ribaf.2021.101396

Peters, N.J., Hofstetter, J.S., Hoffmann, V.H., 2011. Institutional entrepreneurship capabilities for interorganizational sustainable supply chain strategies. International Journal of Logistics Management, vol. 22, no. 1, pp. 52-86. 
Rosca, E., Möllering, G., Rijal, A., Bendul, J.C., 2019. Supply chain inclusion in base of the pyramid markets: A cluster analysis and implications for global supply chains: A cluster analysis and implications for global supply chains. International Journal of Physical Distribution and Logistics Management, vol. 49 , no. 5 , pp. $575-598$.

Rudiac, B., Hubner, S., Baum, M., 2021. Hustlers, hipsters and hackers: Potential employees' stereotypes of entrepreneurial leaders. Journal of Business Venturing Insights, 15(2021) e00220

Schyns, B., Kiefer, T., Foti, R.J. 2020. Does thinking myself as leader make me want to lead? The role of congruence in self-theories and implicit leadership theories in motivation to lead. Journal of Vocational Behavior, 122 (103477), 1-16

Syed Awais, A.T., Fantazy, K., 2018. Exploring the relationships of strategic entrepreneurship and social capital to sustainable supply chain management and organizational performance. International Journal of Productivity and Performance Management, vol. 67, no. 9, pp. 2046-2070.

Ute, S. and Pathak, S., 2016. Beyond cultural values? Cultural leadership ideas and entrepreneurship. Journal of Business Venturing, 31 (2016), pp. 505-523

Vial A.C., Napier J.L., Brescoll V.L., 2016. A bed of thornes : Female leaders and the self reinforcing cycle. The Leadership Quarterly, 27, 400-414

Xie, Y., Xue, W., Li, L., Wang, A.,Chen, Y., Zheng, Q., Wang, Y., Li, X., 2018. Leadership style and innovation atmosphere in enterprises. Technological Forecasting and Social Change, 135, pp. 257-265

Yan, J., Yan, L. 2016. Individual entrepreneurship, collective entrepreneurship and innovation in small business: an empirical study. International Entrepreneurship and Management Journal, vol. 12, no. 4, pp. 1053-1077. 


\section{Appendix 1}

\section{Guide for the interview with tech entrepreneurs in Romania}

\begin{tabular}{|c|c|c|}
\hline Activity & Comments/Questions & $\begin{array}{l}\text { Approximate } \\
\text { Time }\end{array}$ \\
\hline $\begin{array}{c}\text { Purpose } \\
\text { of the interview }\end{array}$ & $\begin{array}{l}\text { Identifying and understanding the main aspects of } \\
\text { entrepreneurship of tech start-ups in Romania }\end{array}$ & leadership and \\
\hline Introduction & $\begin{array}{l}\text { Thank you for agreeing to participate in this interview. } \\
\text { We are interviewing you to better understand your ideas } \\
\text { and opinions related to leadership and entrepreneurship. } \\
\text { There are no right or wrong answers to any of our } \\
\text { questions, we are interested in your own views. } \\
\text { Participation is voluntary. The interview should take } \\
\text { approximately one hour, depending on how much } \\
\text { information you would like to share. All responses will } \\
\text { be shared with research team members, and we will use } \\
\text { the information received from you to build a case study } \\
\text { for teaching purposes. You may decline to answer any } \\
\text { question or stop the interview at any time and for any } \\
\text { reason. } \\
\text { Are there any questions about what I have just } \\
\text { explained? } \\
\text { (the interviewee will read and sign the Interview Consent } \\
\text { Agreement). }\end{array}$ & 5 minutes \\
\hline $\begin{array}{l}\text { Establishing } \\
\text { Rapport }\end{array}$ & $\begin{array}{l}\text { Before we begin, it would be nice if you could tell me a } \\
\text { little bit about yourself and your position/role in the } \\
\text { company. }\end{array}$ & 5 minutes \\
\hline Structured topics & $\begin{array}{l}\text { 1. Introduction and general matters } \\
\text { Can you tell me few general information about you and } \\
\text { your start-up? } \\
\text { Prompts: } \\
\text { - What is your age? } \\
\text { - What is your sex? } \\
\text { - How many years of professional experience do you } \\
\text { - have? } \\
\text { - How many years of entrepreneurial experience do } \\
\text { - What is the number of years in the current start-up? } \\
\text { - What is your target industry/vertical? } \\
\text { - How many FTE do you have now (except founders)? } \\
\text { - What is your current MRR? } \\
\text { - Please shortly describe how you started the company } \\
\text { 2. Impact on innovation and sustainability } \\
\text { - Please rate as low/medium/high your impact on } \\
\text { innovation. Please comment on the degree and } \\
\text { intensity of innovation in your start-up. } \\
\text { Please rate as low/medium/high your impact on }\end{array}$ & 50 minutes \\
\hline
\end{tabular}




\begin{tabular}{|c|c|c|}
\hline Activity & Comments/Questions & $\begin{array}{l}\text { Approximate } \\
\text { Time }\end{array}$ \\
\hline & $\begin{array}{l}\text { sustainability. Please comment on the sustainability } \\
\text { measures that you implemented/will implement in } \\
\text { the future. } \\
\text { - How and what do you think your start-up will disrupt } \\
\text { your industry? } \\
\text { 3. Leadership characteristics of an entrepreneur } \\
\text { - What motivates you as an entrepreneur? } \\
\text { - What motivates you as a leader? } \\
\text { - What do you think that motivate your followers? } \\
\text { - What do you think are the best qualities of an } \\
\text { - entrepreneur/leader? } \\
\text { - In your opinion, which are the main leadership } \\
\text { - How would you define your leadership style- single } \\
\text { choice? } \\
\text { 4. Forward looking statements and outlook } \\
\text { - How do you see your industry in a medium term? } \\
\text { - How do you see your start-up in a medium term? } \\
\text { - What are the strengths that you see in a medium } \\
\text { - Werm? } \\
\text { - What are the weaknesses that you see in a medium } \\
\text { - What are the opportunities that you see in a medium } \\
\text { term? }\end{array}$ & \\
\hline $\begin{array}{l}\text { Closing } \\
\text { comments } \\
\text { and completion } \\
\text { of any } \\
\text { paperwork } \\
\text { provided }\end{array}$ & Is there anything else that you would like to add? & 10 minutes \\
\hline
\end{tabular}

